\title{
Comparison of influenza disease burden in older populations of Hong Kong and Brisbane: the impact of influenza and pneumococcal vaccination
}

\author{
Lin Yang ${ }^{1 *}$ (D, King Pan Chan ${ }^{3}$, Chit Ming Wong ${ }^{3}$, Susan Shui Seng Chiu ${ }^{4}$, Ricardo J. Soares Magalhaes ${ }^{5}$,
} Thuan Quoc Thach ${ }^{3}$, Joseph Syrial Malik Peiris ${ }^{3}$, Archie C. A. Clements ${ }^{6}$ and Wenbiao Hu

\begin{abstract}
Background: Influenza and pneumococcal vaccine uptake in the older population aged 65 years or over of Hong Kong dramatically increased since the 2003 SARS outbreak. This study is aimed to evaluate the impact of increased coverage of influenza and pneumococcal vaccines by comparing the change of disease burden in the older population of Hong Kong, with the burden in the older population of Brisbane with relatively high vaccine coverage in the past fifteen years.

Methods: Time series segmented regression models were applied to weekly numbers of cause-specific mortality or hospitalization of Hong Kong and Brisbane. Annual excess rates of mortality or hospitalization associated with influenza in the older population were estimated for the pre-SARS (reference period), post-SARS and post-pandemic period, respectively. The rate ratios (RRs) between these periods were also calculated to assess the relative change of disease burden.

Results: Compared to the pre-SARS period, excess rates of mortality associated with influenza during the post-SARS period in Hong Kong decreased for cardiorespiratory diseases ( $R R=0.90,95 \% \mathrm{Cl} 0.80,1.01$ ), stroke (RR $=0.74,95 \%$ $\mathrm{Cl} 0.50,1.09$ ), and ischemic heart diseases ( $\mathrm{RR}=0.45,95 \% \mathrm{Cl} 0.34,0.58)$. The corresponding RRs in Brisbane were $0.79(95 \% \mathrm{Cl} 0.54,1.15), 0.33(0.13,0.80)$, and $1.09(0.62,1.90)$, respectively. Only the mortality of ischemic heart diseases showed a greater reduction in Hong Kong than in Brisbane. During the post-pandemic period, excess rates of all-cause mortality increased in Hong Kong, but to a lesser extent than in Brisbane (RR $=1.41$ vs 2.39).

Conclusion: A relative decrease (or less of an increase) of influenza disease burden was observed in the older population of Hong Kong after increased coverage of influenza and pneumococcal vaccines in this population, as compared to those of Brisbane where vaccination rates remained stable. The lack of significant findings in some disease categories highlights the challenges of evaluating the benefits of vaccination at the population level.
\end{abstract}

Keywords: Influenza, Disease burden, Mortality, Morbidity, Elderly, Vaccine

\footnotetext{
*Correspondence: l.yang@polyu.edu.hk

'GH515, School of Nursing, The Hong Kong Polytechnic University, Hung

Hom, Hong Kong, Hong Kong, Special Administrative Region of China

Full list of author information is available at the end of the article
}

(c) The Author(s). 2019 Open Access This article is distributed under the terms of the Creative Commons Attribution 4.0 International License (http://creativecommons.org/licenses/by/4.0/), which permits unrestricted use, distribution, and reproduction in any medium, provided you give appropriate credit to the original author(s) and the source, provide a link to the Creative Commons license, and indicate if changes were made. The Creative Commons Public Domain Dedication waiver (http://creativecommons.org/publicdomain/zero/1.0/) applies to the data made available in this article, unless otherwise stated. 


\section{Background}

Globally, influenza has been associated with a heavy burden of mortality and morbidity [1]. Vaccination remains an important strategy to reduce disease severity and virus transmission within the community [2]. Although numerous clinical trials have demonstrated the effectiveness of influenza vaccines in children [3], adults [4], and healthy elderly people [5], few studies have included high-risk groups particularly the elderly with underlying chronic conditions. A recent systematic review also concluded that influenza vaccine only had a modest effect in preventing influenza infections among community-dwelling elderly people [6]. Previous cohort or case-control studies reported that vaccine effectiveness was $48 \%$ in preventing all-cause mortality [7]. However, according to a study in the US, $<5 \%$ of all-cause mortality was specifically associated with influenza, suggesting that the estimates from the observational studies could have been seriously overestimated $[8,9]$. Another ecological study conducted in Ontario, Canada also found significant relative reductions in influenza-associated mortality and health care utilization after the introduction of universal vaccination since 2000 in those aged $<65$ yrs., but not in those aged $\geq 65$ yrs. [10]. Taken together, available evidence suggests that there is a need to assess the effect of influenza vaccination at the population level, especially for those aged $\geq 65$ years.

Previous studies in Hong Kong have shown that annual vaccination rates for community-dwelling elderly people were less than 3\% during the period 2000-2002 [11], but increased to more than 50\% in 2004-2006 [12]. Since October 2009, a subsidy of HK\$80 (US\$10.30) for annual influenza vaccine and HK\$190 (US\$24.50) for pneumococcal vaccine has been provided to those aged $\geq 65$ years under the Elderly Vaccination Subsidy Scheme. The vaccination rate remained nearly $40 \%$ in the elderly in the 2012/13 season [13]. In Australia, the federal government has been providing free influenza vaccinations for people aged $\geq 65$ years since 1999 , and the coverage rates in the older population remained between 70 and 80\% during the period of 2002-2006 [14]. Unlike Hong Kong, where the SARS outbreak and a new subsidy program greatly increased influenza and pneumococcal vaccine coverage among the older population, Brisbane has had a relatively stable vaccination rate for both vaccines since 2000 . Here we hypothesize that if influenza vaccine was effective in older people, the dramatically increased uptake among the older population of Hong Kong since SARS could have resulted in a reduced influenza disease burden. We expect such a reduction to be larger than in Brisbane, where uptake of the vaccine has remained stable among the community dwelling elderly people. Further decrease in disease burden of influenza could have occurred after 2009, as the increased uptake of pneumococcal vaccines in the older population could have reduced the risk of secondary bacterial pneumonia after influenza infections.

\section{Methods \\ Study population}

Hong Kong is located at a latitude of $22^{\circ} \mathrm{N}$, with a population of 6.9 million in 2006 residing in an area of $1104 \mathrm{~km}^{2}$. Brisbane is located at a latitude of $27^{\circ} \mathrm{S}$, with a population of 1.8 million in 2006 and a territory of $1360 \mathrm{~km}^{2}$. Both Hong Kong and Brisbane have a subtropical climate, with average temperatures of $27^{\circ} \mathrm{C}$ and $20^{\circ} \mathrm{C}$, and relative humidity of 80 and $60 \%$, respectively. In terms of socioeconomic conditions, both are developed cities with a comparable Gross Domestic Product per capita (\$31,514 in Hong Kong vs. $\$ 55,671$ in Australia in 2010) [15]. During the study period, the percentage of the population aged $\geq 65$ years was $12.5 \%$ in Hong Kong and $11.6 \%$ in Brisbane. Virology data, death registry data, hospital admission, and meteorological data during the study period of 2001 to 2012 were obtained from difference data sources of Hong Kong and Brisbane, respectively. The detailed information is provided in Additional file 1: Appendix 1.

\section{Study period}

In Hong Kong, seasonal influenza peaks during January March and June - July, whereas in Australia the peak usually occurs in August - October (Fig. 1). Given that seasonal influenza peaks at different times in these two cites, we defined annual study period as January - December in Hong Kong and May - April of next year in Brisbane. These periods begin three months after the usual launch dates for the annual seasonal influenza vaccination campaigns (March in Brisbane and September in Hong Kong), which shall allow for a valid assessment of the vaccination effectiveness. The whole study period was divided into the pre-SARS, SARS, post-SARS, influenza pandemic and post-pandemic periods. The pre-SARS period in Hong Kong was featured with a much lower vaccination rate in the older population compared to the post-SARS and post-pandemic periods, whereas the vaccination rate in the older population of Brisbane was stable across these periods. The burden during the SARS and pandemic periods was not presented, as this was highly affected by different control measures adopted by the health authorities of Hong Kong and Brisbane. The cut-off dates for these periods in Hong Kong and Brisbane are listed in Additional file 1: Appendix 2.

\section{Statistical analysis}

We constructed time series segmented regression models to estimate cause-specific mortality or hospitalization risks associated with influenza in the older population during the pre-SARS, post-SARS, and post-pandemic periods for Hong Kong and Brisbane. The proxy variable for influenza 


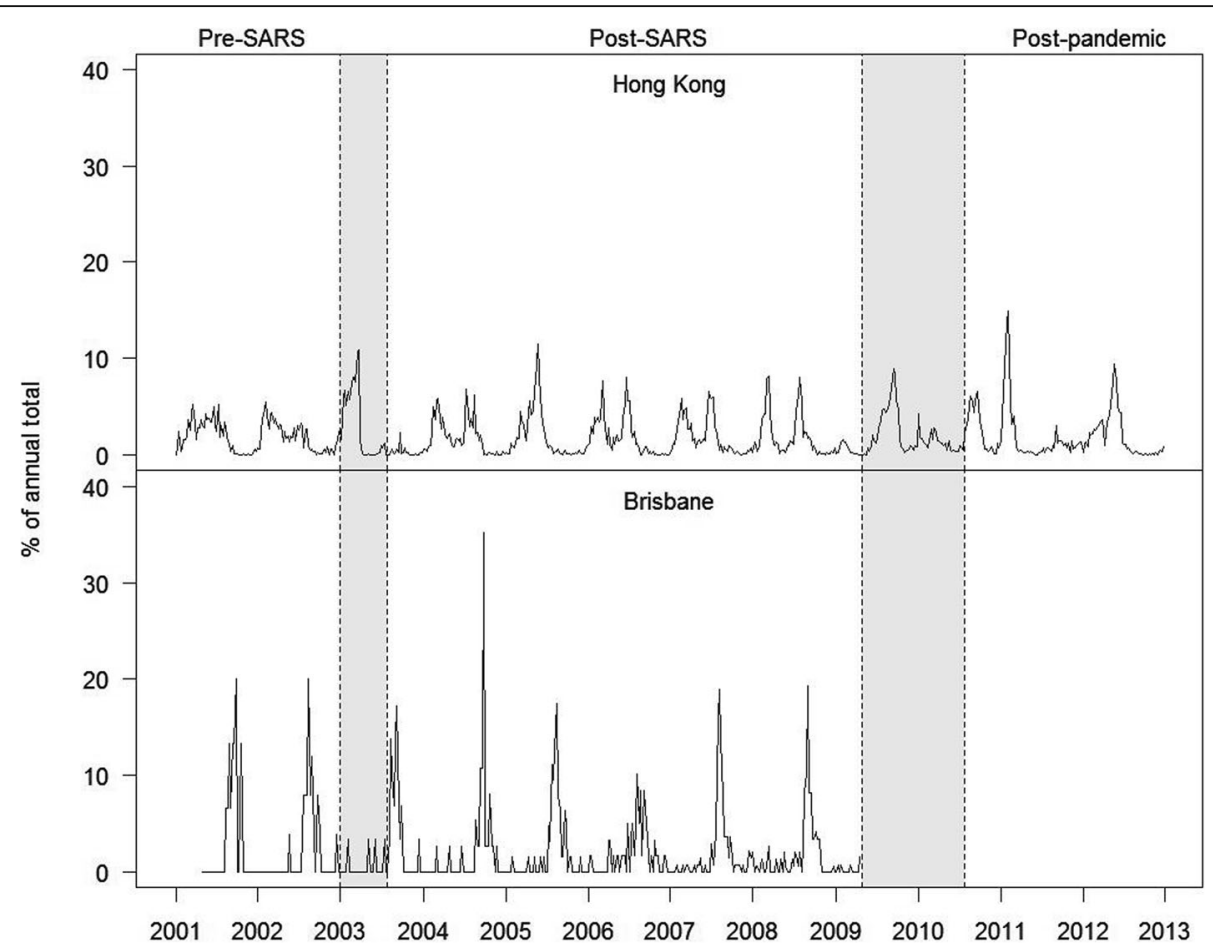

Fig. 1 Time series plots of laboratory confirmed influenza in Hong Kong (upper panel) and Brisbane (lower panel), 2001-2012. The gray bands highlight the SARS period and the $2009 \mathrm{H} 1 \mathrm{~N} 1$ pandemic

in the model was the percentage of specimens that tested positive for influenza each week out of annual total number in each city. The reason why we decided to use annual percentage instead of weekly proportion used in our previous studies is that total numbers of specimens were not available in Brisbane during the whole study period. We added seasonal trends, temperature, humidity, and other respiratory viruses to the model as covariates to estimate influenza-associated excess risks. Dummy variables for the pre-SARS, post-SARS, and post-pandemic periods, together with the interaction terms between these period dummies and the virus activity variables, were also added to test the statistical differences in risk estimates between the different periods, respectively for Hong Kong and Brisbane.

The best-fit models were chosen by the minimal generalized cross-validation (GCV), according to our previous study [16]. Baseline rates of cause-specific mortality and hospitalizations associated with influenza were calculated for different periods by setting the virus proxy to zero and the corresponding period dummy to one (other dummies were simultaneously set to zero). We first estimated excess numbers by subtracting baseline rates from the observed data, and calculated excess rates (ER) by dividing the excess numbers with age-specific population size.

We calculated the $95 \%$ confidence interval (CI) of ER by bootstrapping 1000 times. Because the periods were of different lengths, annual excess rates (AER) of mortality (or hospitalizations) were calculated to facilitate comparisons between different periods. For each disease category, the rate ratios (RRs) of post-SARS (or post-pandemic) versus pre-SARS were derived by dividing annual excess rates during the post-SARS (or post-pandemic) period with those of the pre-SARS period (as reference):

$R R=A E R$ (post-SARS) / AER (pre-SARS).

Since the pre-SARS period was treated as the reference period in this study, hereafter the post-SARS RR refers to the risk ratio of mortality or hospitalization in the postSARS period relative to those in the pre-SARS period. Similarly, the post-pandemic RR refers to the risk ratio of mortality or hospitalization in the post-pandemic period relative to those in the pre-SARS period. The $95 \% \mathrm{CI}$ and $p$-value of $\mathrm{RR}$ were derived from a normal approximation of their logarithmic transformations [17].

We also conducted a subset analysis by using the data of influenza peak seasons only. The influenza season was defined as January to July in Hong Kong, and May to November in Brisbane. We conducted another subset analysis by excluding the data for the mismatched years $(2003,2004$, and 2008 in this study).

All of the analyses were conducted in $\mathrm{R}$ software version 2.5.1. The significance level was set to 0.05 for all analyses.

\section{Results}

During the study period, there were around 860,000 and 112,000 people older than 65 years living in Hong Kong and Brisbane, respectively (Tables 1 and 2). Compared to 
Table 1 Summary statistics of demographic characteristics, mortality, hospitalization, and virological and meteorological data in Hong Kong in different periods

\begin{tabular}{|c|c|c|c|c|c|c|c|c|c|c|c|c|c|c|c|c|}
\hline & \multicolumn{4}{|c|}{ Whole period } & \multicolumn{4}{|c|}{ Pre-SARS } & \multicolumn{4}{|c|}{ Post-SARS } & \multicolumn{4}{|c|}{ Post-pandemic } \\
\hline & Mean & SD & Min. & Max & Mean & SD & Min. & Max & Mean & SD & Min. & Max & Mean & SD & Min. & Max \\
\hline Elderly population (per 1000) & 860.4 & 65.5 & 753.3 & 980.3 & 765.2 & 12 & 753.3 & 777.1 & 850.6 & 28.8 & 795.4 & 898.6 & 953.5 & 24 & 918.5 & 980.3 \\
\hline \multicolumn{17}{|l|}{ Weekly death no. (n) } \\
\hline All-causes & 572.5 & 86.6 & 406 & 869 & 488.6 & 49.5 & 406 & 624 & 569.5 & 76.3 & 415 & 869 & 630.8 & 85.3 & 484 & 869 \\
\hline CRD & 290.7 & 58.8 & 179 & 522 & 240.5 & 35.8 & 179 & 351 & 291.4 & 54.5 & 194 & 522 & 321.3 & 60.9 & 234 & 503 \\
\hline P\&l & 85.3 & 28 & 36 & 190 & 55.1 & 9.6 & 36 & 98 & 80.8 & 21 & 41 & 186 & 115.9 & 25.4 & 71 & 190 \\
\hline COPD & 36 & 9.6 & 12 & 67 & 37 & 9.3 & 19 & 64 & 36.2 & 9.7 & 12 & 65 & 34.2 & 9.4 & 19 & 67 \\
\hline Stroke & 55.6 & 10.9 & 30 & 92 & 52.8 & 10.6 & 32 & 81 & 57.4 & 10.8 & 30 & 92 & 52.8 & 10.6 & 30 & 84 \\
\hline $\mathrm{IHD}$ & 64.1 & 15.4 & 34 & 129 & 53 & 10.8 & 34 & 82 & 66.2 & 15.1 & 37 & 129 & 66.4 & 15.7 & 35 & 120 \\
\hline Accidents & 10.7 & 3.7 & 2 & 23 & 10.2 & 3.7 & 2 & 20 & 10.8 & 3.8 & 3 & 23 & 10.2 & 3.4 & 4 & 20 \\
\hline \multicolumn{17}{|l|}{ Weekly hospitalization no. (n) } \\
\hline CRD & 3542.5 & 958.5 & 1704 & 6340 & 3196.9 & 283.2 & 2535 & 3945 & 2965.3 & 445.4 & 2260 & 4566 & 4858.7 & 485.1 & 3906 & 6079 \\
\hline$P \& \mid$ & 597.9 & 306.7 & 98 & 1497 & 177 & 34 & 111 & 256 & 592.7 & 187.8 & 124 & 1200 & 930.5 & 199.6 & 673 & 1497 \\
\hline COPD & 687.8 & 168.6 & 285 & 1188 & 767.3 & 104.4 & 576 & 1040 & 596.2 & 112.4 & 387 & 1048 & 815.9 & 147.6 & 573 & 1188 \\
\hline Stroke & 635.3 & 211.6 & 329 & 1254 & 611.5 & 60.1 & 471 & 750 & 479.9 & 79.8 & 334 & 766 & 917.7 & 92.5 & 723 & 1166 \\
\hline $\mathrm{IHD}$ & 659.4 & 225.1 & 257 & 1368 & 583.7 & 63 & 471 & 718 & 516.3 & 90.1 & 374 & 866 & 958.4 & 109.7 & 711 & 1279 \\
\hline Accidents & 493.2 & 115.4 & 267 & 845 & 430.6 & 39.3 & 354 & 547 & 434 & 61.8 & 325 & 634 & 656.8 & 55.1 & 549 & 845 \\
\hline Weekly positive specimens (n) & 19.8 & 32.8 & 0 & 310 & 11.8 & 9.7 & 0 & 41 & 13.6 & 15.8 & 0 & 93 & 23.9 & 30.9 & 0 & 157 \\
\hline $\begin{array}{l}\text { Weekly positive percentage } \\
(\%)\end{array}$ & 1.9 & 2.2 & 0 & 14.9 & 1.9 & 1.5 & 0 & 5.6 & 1.7 & 2 & 0 & 11.5 & 2.1 & 2.7 & 0 & 14.9 \\
\hline Temperature $\left({ }^{\circ} \mathrm{C}\right)$ & 23.5 & 4.9 & 11.4 & 30.5 & 23.8 & 4.5 & 14.1 & 30.2 & 23.2 & 4.8 & 11.4 & 30.5 & 23.4 & 5.2 & 12.3 & 30.1 \\
\hline Relative Humidity (\%) & 78.3 & 7.8 & 51 & 93.7 & 78.5 & 7.5 & 54.4 & 92 & 77.7 & 8.3 & 51 & 93.6 & 77.9 & 7.5 & 54.9 & 93.7 \\
\hline
\end{tabular}

Note. Weekly positive percentage (\%) is defined as the percentage of positive specimens among annual total specimens

Hong Kong, during the study period Brisbane had higher mortality rates for all-cause (81.7 vs 66.5 per 100,000 population), cardiorespiratory diseases (CRD, 42.1 vs 33.8), stroke (9.5 vs 6.5) and ischemic heart diseases (IHD, 17.0 vs 7.5), but a lower rate for pneumonia and influenza (P\&I, 2.8 vs 9.9), and a comparable rate for chronic obstructive pulmonary disease (COPD, 3.9 vs 4.2) (Additional file 1: Appendix 3). All the cause-specific hospitalization rates were much lower in Brisbane than in Hong Kong (233.6 vs 411.7 per 100,000 population for CRD, 21.7 vs 69.5 for P\&I, 39.7 vs 79.9 for COPD, 19.4 vs 73.8 for stroke), with the only exception of IHD (65.1 vs 76.6) (Additional file 1: Appendix 4). Hong Kong and Brisbane have opposite seasonal climate patterns; the former is located in the Northern Hemisphere and the latter in the Southern Hemisphere. Mean temperature and relative humidity of Brisbane were lower than those of Hong Kong (Additional file 1: Appendix 5).

Compared to the pre-SARS period, average number of hospitalizations in Hong Kong was lower in the post-SARS period for most disease categories, with the exception of a three-fold increase in P\&I hospitalizations. This significant increase is likely due to the change in coding practice after the SARS outbreak (Table 1). Average number of hospitalizations was higher in the post-pandemic period for all the disease categories. Weekly figures for mortality and hospitalization in Brisbane did not obviously differ across the pre-SARS, post-SARS, and post-pandemic periods (Table 2).

Due to negative estimates in the annual excess rates for mortality, the post-SARS RR could not be estimated for IHD hospitalizations in Hong Kong, and P\&I mortality, stroke, and IHD hospitalizations in Brisbane. Similarly, the post-pandemic RR could not be estimated for P\&I and IHD hospitalization in Hong Kong, and stroke and COPD hospitalization in Brisbane (Additional file 1: Appendix 6). Influenza-associated all-cause mortality rates were found increased after SARS in Hong Kong (post-SARS vs preSARS $R R=1.22)$ but decreased in Brisbane $(R R=0.87)$. The post-SARS COPD mortality increased in both cities (1.04 and 1.03 in Hong Kong and Brisbane, Table 3). Decreased excess rates of mortality in Hong Kong were observed for CRD, stroke, and IHD mortality $(R R=0.90$ and 0.74), while the corresponding RRs in Brisbane were 0.79 and 0.33 , respectively. Only IHD mortality had a greater reduction observed in Hong Kong than in 
Table 2 Summary statistics of demographic characteristics, mortality, hospitalization, and virological and meteorological data in Brisbane in different periods

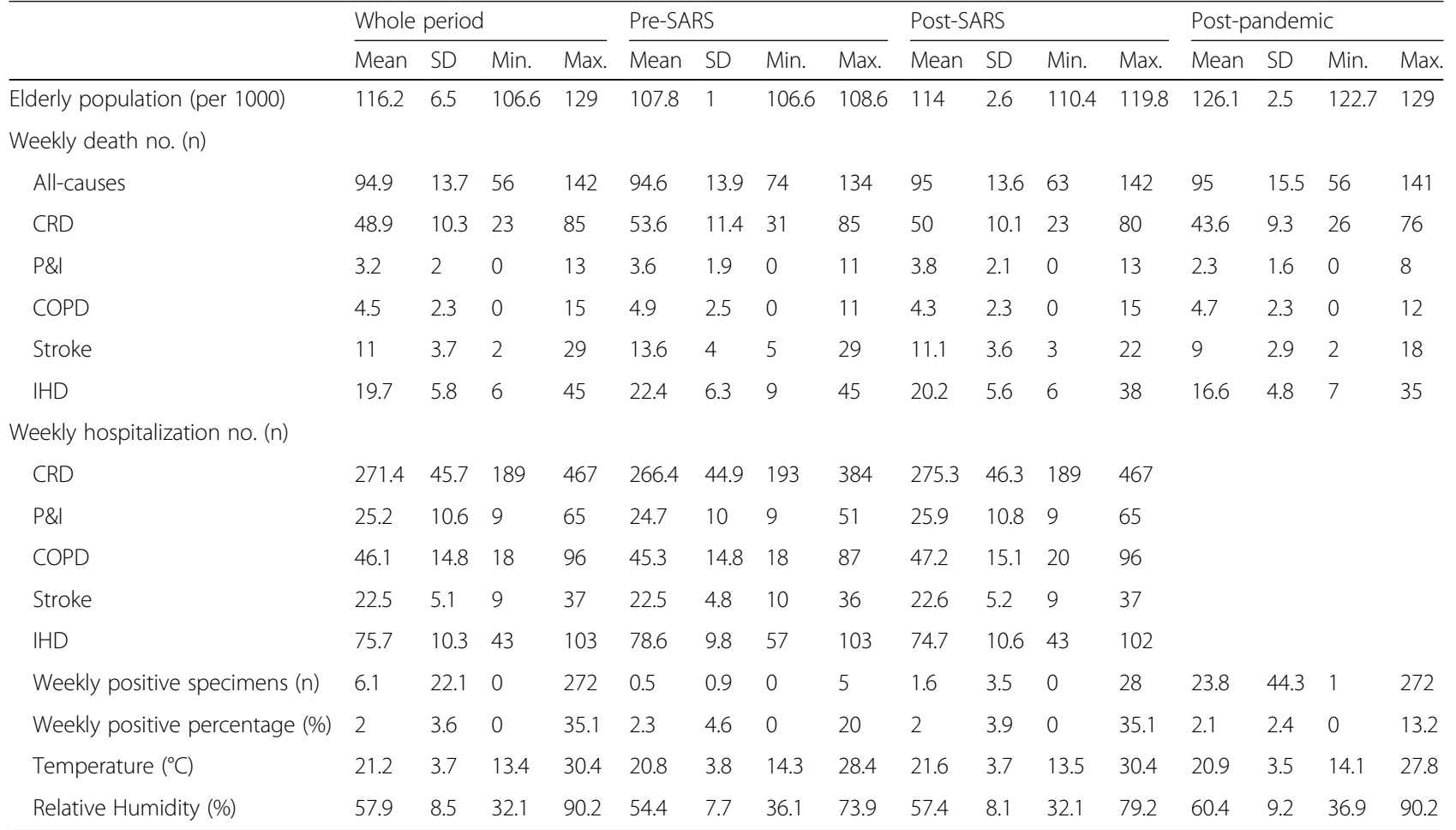

Note. Weekly positive percentage (\%) is defined as the percentage of positive specimens among annual total specimens

Brisbane $(R R=0.45$ vs 1.09$)$. None of $R R$ estimates for the control disease injuries were significant (data not shown).

Compared to the pre-SARS period, excess rates of CRD hospitalizations in the post-SARS period decreased in Hong Kong, but increased markedly in Brisbane $(R R=0.86$ vs 26.82). Influenza-associated hospitalizations for P\&I and COPD increased more in Brisbane than in Hong Kong ( $\mathrm{RR}=3.49$ vs 2.79 and 1.33 vs 1.04 ).

Compared to the pre-SARS period, excess mortality rates increased in Hong Kong for all the disease categories except for IHD, but only all-cause and COPD mortality increased in Brisbane. Difference between Hong Kong and Brisbane was found statistically significant for all-cause and stroke mortality. Annual excess rates of all-cause mortality increased in Hong Kong to a lesser extent than in Brisbane $(R R=1.41$ vs 2.39 ), whereas an opposite trend was observed for stroke mortality $(\mathrm{RR}=1.26$ vs 0.29$)$.

Subset analysis with peaks seasons only, or vaccine matched years only, generally derived larger RR estimates (Table 3). The estimates for CRD became significantly higher than one, and the Brisbane estimates were much greater than the Hong Kong ones. Many outcomes could not be estimated due to negative values of excess rates.

\section{Discussion}

In this study, we estimated excess rates of mortality or hospitalizations attributable to influenza in different periods (pre-SARS, post-SARS, and post-pandemic) for two subtropical cities Hong Kong and Brisbane. We hypothesized that the influenza disease burden decreased more, or increased less, in Hong Kong than in Brisbane since 2003, because the uptake rate of influenza and pneumococcal vaccines increased more markedly in Hong Kong than in Brisbane during the same period. Kwong et al. [10] compared the relative change of disease burden in Ontario, where a universal influenza vaccination program was launched, to that in other Canadian provinces without such a policy. They found that influenza-associated mortality fell in Ontario and other provinces, but a larger reduction occurred in Ontario. In this study, we found that excess rates of IHD mortality decreased more from the pre-SARS to the post-SARS period in Hong Kong than in Brisbane, but with regard to the other mortality outcomes, excess rates increased more in Hong Kong. With respect to hospitalization in the post-SARS period, significantly lower excess rates were only found for CRD in Hong Kong. P\&I and COPD hospitalization rates increased in both cities, but to a lesser extent in Hong Kong.

Many countries have recommended annual influenza vaccination or providing subsidy programs to the older 
Table 3 Rate ratio (RR) of excess mortality or hospitalization associated with influenza between the post-SARS and pre-SARS (reference) periods in Hong Kong and Brisbane; and the ratio of RR (RRR) between Hong Kong (HK) and Brisbane

\begin{tabular}{|c|c|c|c|c|c|c|c|c|c|c|c|c|}
\hline & \multicolumn{4}{|c|}{ Whole period } & \multicolumn{4}{|c|}{ Peak seasons only ${ }^{\text {aPeak seasons onlya }}$} & \multicolumn{4}{|c|}{ Vaccine matched years onlybVaccine ${ }^{\text {matched years onlyb }}$} \\
\hline & \multicolumn{2}{|c|}{ Hong Kong } & \multicolumn{2}{|c|}{ Brisbane } & \multicolumn{2}{|c|}{ Hong Kong } & \multicolumn{2}{|c|}{ Brisbane } & \multicolumn{2}{|c|}{ Hong Kong } & \multicolumn{2}{|c|}{ Brisbane } \\
\hline & $\mathrm{RR}$ & $95 \% \mathrm{Cl}$ & $\mathrm{RR}$ & $95 \% \mathrm{Cl}$ & RR & $95 \% \mathrm{Cl}$ & RR & $95 \% \mathrm{Cl}$ & $\mathrm{RR}$ & $95 \% \mathrm{Cl}$ & $\mathrm{RR}$ & $95 \% \mathrm{Cl}$ \\
\hline \multicolumn{13}{|c|}{ Mortality Post-SARS vs Pre-SARS } \\
\hline All-causes & 1.22 & $(1.10,1.35)$ & 0.87 & $(0.62,1.21)$ & 1.48 & $(1.35,1.63)$ & 0.93 & $(0.72,1.19)$ & 2.62 & $(2.25,3.05)$ & 4.39 & $(2.67,7.22)$ \\
\hline CRD & 0.90 & $(0.80,1.01)$ & 0.79 & $(0.54,1.15)$ & 1.11 & $(1.00,1.23)$ & 3.54 & $(2.23,5.62)$ & 1.25 & $(1.08,1.45)$ & 4.75 & $(2.55,8.83)$ \\
\hline P\&l & 2.50 & $(2.00,3.13)$ & $\mathrm{NE}$ & & 1.26 & $(1.06,1.49)$ & $\mathrm{NE}$ & & 1.53 & $(1.23,1.91)$ & $\mathrm{NE}$ & \\
\hline COPD & 1.04 & $(0.78,1.38)$ & 1.03 & $(0.44,2.39)$ & $\mathrm{NE}$ & & 1.71 & $(0.54,5.37)$ & $\mathrm{NE}$ & & 1.39 & $(0.62,3.13)$ \\
\hline Stroke & 0.74 & $(0.50,1.09)$ & 0.33 & $(0.13,0.80)$ & $\mathrm{NE}$ & & 0.31 & $(0.14,0.71)$ & 1.18 & $(0.81,1.71)$ & 0.58 & $(0.28,1.20)$ \\
\hline IHD & 0.45 & $(0.34,0.58)$ & 1.09 & $(0.62,1.90)$ & 0.48 & $(0.40,0.58)$ & 1.36 & $(0.81,2.27)$ & 0.16 & $(0.11,0.23)$ & $\mathrm{NE}$ & \\
\hline \multicolumn{13}{|c|}{ Hospitalization Post-SARS vs Pre-SARS } \\
\hline CRD & 0.86 & $(0.82,0.91)$ & 26.82 & $(9.56,75.24)$ & 5.25 & $(4.86,5.68)$ & $\mathrm{NE}$ & & 15.83 & $(13.50,18.56)$ & 28.09 & $(9.80,80.53)$ \\
\hline$P \&$ & 2.79 & $(2.57,3.03)$ & 3.49 & $(1.96,6.21)$ & 5.18 & $(4.74,5.67)$ & $\mathrm{NE}$ & & 6.37 & $(5.65,7.19)$ & 2.02 & $(1.20,3.40)$ \\
\hline COPD & 1.04 & $(0.96,1.14)$ & 1.33 & $(0.91,1.93)$ & 9.12 & $(7.77,10.71)$ & 1.35 & $(0.96,1.89)$ & $\mathrm{NE}$ & & 1.10 & $(0.76,1.59)$ \\
\hline Stroke & 0.15 & $(0.12,0.19)$ & $\mathrm{NE}$ & & 0.02 & $(0.01,0.05)$ & $\mathrm{NE}$ & & $\mathrm{NE}$ & & $\mathrm{NE}$ & \\
\hline $\mathrm{HD}$ & $\mathrm{NE}$ & & $\mathrm{NE}$ & & $\mathrm{NE}$ & & $\mathrm{NE}$ & & $\mathrm{NE}$ & & $\mathrm{NE}$ & \\
\hline \multicolumn{13}{|c|}{ Mortality Post-pandemic vs Pre-SARS } \\
\hline All-causes & 1.41 & $(1.28,1.56)$ & 2.39 & $(1.83,3.12)$ & 1.16 & $(1.06,1.28)$ & 2.06 & $(1.67,2.55)$ & 2.96 & $(2.55,3.44)$ & 7.21 & $(4.48,11.62)$ \\
\hline CRD & 1.16 & $(1.04,1.29)$ & 0.98 & $(0.69,1.38)$ & 1.06 & $(0.96,1.18)$ & 4.10 & $(2.61,6.44)$ & 1.48 & $(1.29,1.71)$ & 2.19 & $(1.12,4.27)$ \\
\hline$P \& l$ & 2.44 & $(1.95,3.05)$ & $\mathrm{NE}$ & & 1.51 & $(1.28,1.77)$ & NE & & 1.69 & $(1.37,2.09)$ & $\mathrm{NE}$ & \\
\hline COPD & 1.07 & $(0.81,1.41)$ & 1.75 & $(0.83,3.67)$ & $\mathrm{NE}$ & & 7.42 & $(2.82,19.54)$ & $\mathrm{NE}$ & & 1.86 & $(0.87,3.96)$ \\
\hline Stroke & 1.26 & $(0.90,1.77)$ & 0.29 & $(0.12,0.72)$ & $\mathrm{NE}$ & & 0.77 & $(0.42,1.39)$ & 1.43 & $(1.01,2.03)$ & 0.43 & $(0.20,0.93)$ \\
\hline IHD & 0.74 & $(0.59,0.92)$ & $\mathrm{NE}$ & & 0.34 & $(0.27,0.41)$ & NE & & 0.40 & $(0.31,0.51)$ & $\mathrm{NE}$ & \\
\hline
\end{tabular}

Note: NE, not estimated due to negative estimates in annual excess rates.The p-value of the RRR of Hong Kong versus Brisbane was calculated from z-tests a Influenza peak season is January to July in Hong Kong, May to November in Brisbane

b The data of years 2003, 2004 and 2008 were excluded due to mismatch between vaccine composite and circulating influenza strains

population [18]. However, due to ethical concerns, a large body of knowledge on the effectiveness of influenza vaccine in the older population has been derived from observational studies, as few randomized controlled trials have been conducted in this high-risk population. A review by Goodwin et al. found that seroprotection and seroconversion achieved in the older population after vaccination was only $25-50 \%$ of vaccine response in younger adults [19]. A Cochrane review concluded that influenza vaccines were of limited effects, which could probably be explained by weak antibody response in the older population [6]; however, in a recent reanalysis using the same data, Walter et al. made the opposite conclusion [20]. They estimated that influenza vaccine resulted in a $30 \%$ reduction in complications after influenza infections, $40 \%$ in influenza-like illnesses, and $50 \%$ in laboratory confirmed influenza infections, specifically during influenza epidemics. However, there is still an on-going debate on vaccine effectiveness in the older population. Our findings add some evidence of a decrease, or a slow increase, in influenza-associated disease burden among the older population, following a marked increase in influenza vaccine coverage at the population level. However, it should be noted that this effect could have been partially caused by an increase of pneumococcal vaccination at the same time. Given that the effectiveness of influenza vaccine is affected by many factors including pre-existing immunity, antigenic shift, and underlying condition, it is not surprising that we failed to find consistent and significant estimates. This also highlights the challenges of evaluating the benefits of vaccination at the population level, even in the most susceptible older populations.

A higher disease burden was found in both Hong Kong and Brisbane after 2003, which was consistent with the findings of our previous studies and others $[21,22]$. The potential explanation could be that H3N2 was more often predominant after 2003 and this subtype has been found associated with higher disease burden than H1N1 and B. The point estimates of RRs were sensitive to modeling parameters, and most had wide confidence intervals. This could be due to only a 
relatively small proportion of deaths or hospitalizations attributable to influenza. According to our previous studies, each year influenza is associated with nearly 1000 deaths and 10,000 hospitalizations in Hong Kong, accounting for only 3 and $1 \%$ of annual total deaths and hospitalizations, respectively [22-25]. Negative estimates of excess rates were occasionally derived from some disease outcomes, making it difficult to assess the relative increase/decrease between two cities. Relatively small counts in Brisbane could be the reason why we obtained extremely large or small point estimates for the post-SARS RR of CRD hospitalizations and the post-pandemic RR of stroke mortality in Brisbane; hence, these RRs need to be interpreted with caution. Unfortunately, good quality mortality, hospitalization, influenza surveillance and vaccination data are available in few subtropical countries/regions. Nevertheless, this study is the first to investigate the effectiveness of influenza and pneumococcal vaccination at the population level in warm climates, to our best knowledge.

There are several limitations in this study. First, ecological fallacy is unavoidable given the ecological study design. Individual vaccination status of those who have died or been hospitalized is unknown and the outcome variables are not specific to influenza. Nevertheless, we have used a previously validated modeling approach to estimate disease burden associated with influenza. Second, we assume that circulating influenza strains and pre-exisitng immunity at the population level are similar between Hong Kong and Brisbane. Therefore, a relative decrease (or less of an increase) in influenza-associated disease burden could reflect the effectiveness of influenza vaccination in terms of reducing adverse outcomes after influenza infections. This assumption may not hold, but there is also no strong evidence against it. Third, only two to five years of data were included in each study period, because influenza virology and hospitalization data prior to 2000 were not available in Hong Kong or Brisbane. Our model obtained some unstable points estimates, especially in the pre-SARS period, which could be due to the short time series and low counts. Last but not least, although we have carefully adjusted for seasonal trends, temperatures, and humidity in our models, there are many confounding factors that remain unadjusted for in this study, such as the prevalence of underlying condition, and difference in health-seeking behaviors between two older populations.

In conclusion, we found some but limited evidence that markedly increased rates of influenza and pneumococcal vaccination among the Hong Kong older people did lead to a reduction in their influenza disease burden. However, furture cohort studies with individual data are warranted to provide stronger evidence to support the promotion of influenza vaccination among the older population.

\section{Additional file}

Additional file 1: Appendix 1. Additional information on data sources and statistical analysis. Appendix 2. Study periods defined for Hong Kong and Brisbane. Appendix 3. Time series plots of weekly numbers of cause-specific mortality data of Hong Kong (black line) and Brisbane (gray line). Appendix 4. Time series plots of weekly numbers of hospital admissions of Hong Kong (black line) and Brisbane (gray line). Hospitalization data of Brisbane are not available in the post-pandemic period. Appendix 5. Time series plots of weekly mean temperature and relative humidity Hong Kong (black line) and Brisbane (gray line). Appendix 6. Annual excess rates of mortality and hospitalizations associated with influenza per 1000,000 population in Hong Kong and Brisbane, 2001-2012. (DOCX 484 kb)

\section{Abbreviations}

AER: Annual excess rate; Cl: Confidence interval; COPD: Chronic obstructive pulmonary disease; CRD: Cardiorespiratory diseases; ER: Excess rates; IHD: Ischemic heart diseases; P\&l: Pneumonia and influenza; RR: Rate ratio; SARS: Severe Acute Respiratory Syndrome

\section{Acknowledgments}

We thank the Census and Statistics Department, Hospital Authority of Hong Kong, Hong Kong Observatory, Australian Bureau of Meteorology, Australian Institute of Health and Welfare, Department of Health of the Australian Government, and Queensland Health Australia for providing the datasets used in this study.

\section{Funding}

This study was supported by Health and Medical Research Fund (grant number:13121282), from the Research Fund Secretariat, Food and Health Bureau, the Government of the Hong Kong Special Administrative Region. The study sponsor was not involved in study design, data collection, analysis, and interpretation of data; nor in the writing of the report and in the decision to submit the paper for publication. The corresponding author had full access to all the data in the study and had final responsibility for the decision to submit for publication.

\section{Availability of data and materials}

Administrative permissions from the data providers were required to access the raw data provided by the Census and Statistics Department, Hospital Authority of Hong Kong, Australian Institute of Health and Welfare, Department of Health of the Australian Government, and Queensland Health Australia). Meteorological data are available at the websites of the Hong Kong Observatory and Australian Bureau of Meteorology. The R scripts used in this study are available from the corresponding author on request.

\section{Authors' contributions}

LY, CMW, SSSC, JSM and WBH designed the study and collected data. LY and KPC conducted data analysis and drafted the manuscript. SSSC, RJSM, TQT, ACAC and WBH interpreted the results and finalized manuscript. All the authors gave final approval of the version to be published.

\section{Ethics approval and consent to participate}

Because no personal data was collected, individual consent was not required. The ethical approval was obtained from the Institutional Review Board of the University of Hong Kong/Hospital Authority Hong Kong West Cluster (reference number UW13-421) and from the Departmental Research Committee of the School of Nursing, The Hong Kong Polytechnic University (reference number HSEARS20150612001).

\section{Consent for publication}

Not applicable.

Competing interests

The authors declare that they have no competing interests.

\section{Publisher's Note}

Springer Nature remains neutral with regard to jurisdictional claims in published maps and institutional affiliations. 


\section{Author details}

'GH515, School of Nursing, The Hong Kong Polytechnic University, Hung Hom, Hong Kong, Hong Kong, Special Administrative Region of China. ${ }^{2}$ School of Public Health and Social Work, Queensland University of Technology, Brisbane, Australia. ${ }^{3}$ School of Public Health, The University of Hong Kong, Hong Kong, Hong Kong, Special Administrative Region of China. ${ }^{4}$ Department of Pediatrics and Adolescent Medicine, The University of Hong Kong, Hong Kong, Hong Kong, Special Administrative Region of China. ${ }^{5}$ School of Veterinary Science, University of Queensland, Brisbane, Australia. ${ }^{6}$ Research School of Population Health, The Australian National University, Canberra, Australia.

Received: 19 June 2018 Accepted: 21 January 2019 Published online: 14 February 2019

\section{References}

1. Glezen WP. Emerging infections: pandemic influenza. Epidemiol Rev. 1996;18(1):64-76

2. WHO. Influenza vaccines. Wkly Epidemiol Rec. 2005;80(33):279-87.

3. Jefferson T, Smith S, Demicheli V, Harnden A, Rivetti A, Di PC. Assessment of the efficacy and effectiveness of influenza vaccines in healthy children: systematic review. Lancet. 2005;365(9461):773-80.

4. Jefferson TO, Rivetti D, Di PC, Rivetti A, Demicheli V. Vaccines for preventing influenza in healthy adults. Cochrane Database Syst Rev. 2007;2:CD001269.

5. Jefferson T, Rivetti D, Rivetti A, Rudin M, Di PC, Demicheli V. Efficacy and effectiveness of influenza vaccines in elderly people: a systematic review. Lancet. 2005;366(9492):1165-74.

6. Jefferson T, Di Pietrantonj C, Al-Ansary LA, Ferroni E, Thorning S, Thomas RE. Vaccines for preventing influenza in the elderly. Cochrane Database Syst Rev. 2010;2:CD004876.

7. Nichol KL, Nordin JD, Nelson DB, Mullooly JP, Hak E. Effectiveness of influenza vaccine in the community-dwelling elderly. N Engl J Med. 2007;357(14):1373-81.

8. Simonsen L, Taylor RJ, Viboud C, Miller MA, Jackson LA. Mortality benefits of influenza vaccination in elderly people: an ongoing controversy. Lancet Infect Dis. 2007;7(10):658-66.

9. Simonsen L, Reichert TA, Viboud C, Blackwelder WC, Taylor RJ, Miller MA Impact of influenza vaccination on seasonal mortality in the US elderly population. Arch Intern Med. 2005;165(3):265-72.

10. Kwong JC, Stukel TA, Lim J, McGeer AJ, Upshur RE, Johansen H, Sambell C, Thompson WW, Thiruchelvam D, Marra F, et al. The effect of universal influenza immunization on mortality and health care use. PLoS Med. 2008;5(10):e211.

11. Hui SL, Chu LW, Peiris JSM, Chan KH, Chu D, Tsui W. Immune response to influenza vaccination in community-dwelling Chinese elderly persons. Vaccine. 2006:24(25):5371-80

12. Cowling BJ, Fung RO, Cheng CK, Fang VJ, Chan KH, Seto WH, Yung R, Chiu B, Lee $\mathrm{P}$, Uyeki TM, et al. Preliminary findings of a randomized trial of non-pharmaceutical interventions to prevent influenza transmission in households. PLoS One. 2008;3(5):e2101.

13. CHP. Seasonal influenza vaccination coverage survey for the $2012 / 13$ season. In: Communicable Diseases Watch. Vol. 10. Hong Kong; 2013.

14. Australian Institute of Health and Welfare: 2002 Influenza vaccine survey: summary results. In;2003.

15. International Monetary Fund: World economic outlook Database 2011. In.

16. Wang XL, Yang L, Chan KP, Chiu SS, Chan KH, Peiris JS, Wong CM. Model selection in time series studies of influenza-associated mortality. PLoS One. 2012;7(6):e39423.

17. Rothman KJ, Greenland S, Lash TL. Modern Epidemiology. Philadelphia: Lippincott Williams \& Wilkins; 2008.

18. van Essen GA, Palache AM, Forleo E, Fedson DS. Influenza vaccination in 2000: recommendations and vaccine use in 50 developed and rapidly developing countries. Vaccine. 2003;21(16):1780-5.

19. Goodwin K, Viboud C, Simonsen L. Antibody response to influenza vaccination in the elderly: a quantitative review. Vaccine. 2006;24(8):1159-69.

20. Beyer W, McElhaney J, Smith D, Monto A, Nguyen-van -Tam J, Osterhaus A. Cochrane re-arranged: support for policies to vaccinate elderly people against influenza. Vaccine. 2013;31(50):6030-3.

21. Wu P, Goldstein E, Ho LM, Yang L, Nishiura H, Wu JT, Ip DKMC, K S, Tsang T, Cowling BJ. Excess mortality associated with influenza a and B virus in Hong Kong, 1998-2009. J Infect Dis. 2012;206(12):1862-71.
22. Yang L, Chan KP, Cowling BJ, Chiu SS, Chan KH, Peiris JS, Wong CM. Excess mortality associated with the 2009 pandemic of influenza a(H1N1) in Hong Kong. Epidemiol Infect. 2012;140(9):1542-50.

23. Wang XL, Yang L, Chan KH, Chan KP, Cao PH, Lau EH, Peiris JS, Wong CM. Age and sex differences in rates of influenza-associated hospitalizations in Hong Kong. Am J Epidemiol. 2015;182(4):335-44.

24. Ou CQ, Wong CM, Ho SY, Schooling M, Yang L, Hedley AJ, Lam TH. Dietary habits and the short-term effects of air pollution on mortality in the Chinese population in Hong Kong. J Epidemiol Community Health. 2012;66(3):254-8.

25. Wong CM, Yang L, Chan KP, Leung GM, Chan KH, Guan Y, Lam TH, Hedley AJ, Peiris JS. Influenza-associated hospitalization in a subtropical city. PLoS Med. 2006;3(4):e121.
Ready to submit your research? Choose BMC and benefit from:

- fast, convenient online submission

- thorough peer review by experienced researchers in your field

- rapid publication on acceptance

- support for research data, including large and complex data types

- gold Open Access which fosters wider collaboration and increased citations

- maximum visibility for your research: over $100 \mathrm{M}$ website views per year

At $\mathrm{BMC}$, research is always in progress.

Learn more biomedcentral.com/submissions 